\title{
Efek Penambahan Serat Gelas pada Komposit Polyurethane Terhadap Sifat Mekanik dan Sifat Fisik Komposit Doorpanel
}

\author{
Astrit Kirana, Moh. Farid, Vania Mitha Pratiwi \\ Jurusan Teknik Material \& Metalurgi, Fakultas Teknologi Industri, Institut Teknologi Sepuluh \\ Nopember (ITS) \\ Jl. Arief Rahman Hakim, Surabaya 60111 Indonesia \\ e-mail: mofaredo@gmail.com
}

\begin{abstract}
Abstrak-Penelitian ini dilakukan untuk membuat material komposit polyurethane berpenguat serat gelas untuk aplikasi di doorpanel. Pengujian yang dilakukan yaitu uji lentur (ASTM D790), uji Tarik (ASTM D-3039 00), dan uji densitas (ASTM C271-99). Dengan perbandingan PU murni (70PPI:30PPG) dan dengan variasi fraksi massa $5 \%, 10 \%$, dan $15 \%$. Hasil Bending menunjukkan kekuatan bending tertinggi dicapai oleh PU murni (70PPPI:30PPG) sebesar 55.88MPa dan hasil Kekuatan Tarik tertinggi dicapai oleh komposit PU-15\% Serat gelas sebesar 2.7 MPa. Hasil pengujian komposisi penyusun polyurethane 70:30 murni didapat densitas sebesar $0.11 \mathrm{~g} / \mathrm{cm}^{3}$. Sementara pada komposisi komposit PU-Serat gelas diketahui bahwa pada fraksi massa $5 \%$ didapat densitas sebesar $0.05 \mathrm{~g} / \mathrm{cm}^{3}$, kemudian pada fraksi massa $10 \%$ densitas meningkat menjadi $0.09 \mathrm{~g} / \mathrm{cm}^{3}$ dan pada $15 \%$ meningkat menjadi $0.10 \mathrm{~g} / \mathrm{cm}^{3}$.
\end{abstract}

Kata Kunci—polyurethane, serat gelas, sifat fisik, sifat mekanik

\section{PENDAHULUAN}

$\mathrm{D}$ EWASA ini perkembangan teknologi bahan semakin pesat. Pemenuhan kebutuhan akan bahan dengan karakteristik tertentu juga menjadi faktor pendorongnya. Berbagai macam bahan telah digunakan dan juga penelitian lebih lanjut terus dilakukan untuk mendapatkan bahan yang tepat guna, salah satunya bahan komposit polyurethane. Kemampuannya yang mudah dibentuk sesuai kebutuhan, baik dalam segi kekuatan maupun keunggulan sifat-sifat yang lain, mendorong penggunaan bahan komposit ppolyurethane sebagai bahan alternatif atau bahan pengganti material logam konvensional pada berbagai produk yang dihasilkan oleh industri khususnya industri otomotif.

Material komposit yaitu material yang tersusun dari campuran atau kombinasi dua atau lebih unsur-unsur utama yang secara makro berbeda di dalam bentuk dan atau komposisi material yang pada dasarnya tidak dapat dipisahkan [1]. Kelebihan material komposit dibandingkan dengan logam adalah ketahanan terhadap korosi atau pengaruh lingkungan bebas dan untuk jenis komposit tertentu memiliki kekuatan dan kekakuan yang lebih baik. Oleh karena itu penelitian yang berkelanjutan berbanding lurus dengan perkembangan teknologi bahan tersebut khususnya komposit.

Penelitian mengenai material komposit maupun komponen yang terbuat dari material komposit telah banyak dilakukan. Pengaruh jenis serat pada komposit terhadap kekuatan tarik bahan komposit polimer/serat gelas [2]. Hasil penelitian tersebut menunjukkan bahwa jenis serat E-glass dengan tipe chopped strand mat memiliki kekuatan tarik sebesar 75,55 MPa. Serat juga dijadikan bahan pada penelitian Farid, dkk. Sebagai pembuatan komposit [3] [4]. Dengan penggabungan matriks polyurethane dan serat gelas diharapkan mendapatkan sifat mekanik yang tinggi untuk yang sesuai di doorpanel. Hal ini mendorong penulis untuk melakukan penelitian lebih lanjut.

Adapun dalam penelitian ini karakteristik komposit yang ingin diketahui adalah sifat kelenturan, kekuatan, dan densitas dari komposit polimer berpenguat serat gelas dan komposit polyurethane berpenguat serat bambu. Hal ini dikarenakan peneliti ingin memperoleh bahan komposit yang kuat, lentur, dan juga ringan. Sehingga uji yang perlu dilakukan harus dapat mengetahui karakteristik komposit polimer yang sesuai, yaitu uji lentur, uji tarik dan uji densitas sehingga aplikasinya sesuai untuk digunakan di doorpanel

\section{METODE PENELITIAN}

\section{A. Material}

Material yang digunakan ialah Polyurethane yang terdiri dari gabungan Polyurethane A (Isocyanate) dengan Polyurethane B (Polyol) sebagai matriksnya dan Serat gelas sebagai fillernya yang didapatkan dari PT Justus Kimia Raya, Surabaya.

\section{B. Preparasi spesimen}

Pengolahan serat gelas digunting kecil-kecil dan dicacah dengan ukuran 250-450 mikron. Metode pembuatan komposit bermatriks PU-fiberglasss ini menggunakan metode blending. Polyurethane A dan polyurethane B dengan perbandingan 70 PPI : 30 PPG dan serat gelas dengan variasi fraksi massa 5\%, $10 \%$ dan $15 \%$ diaduk secara merata lalu dituangkan kedalam cetakan sebelum terjadi proses pengembangan busa. Pembuatan cetakan untuk uji bending menggunakan seng yang dibentuk dengan dimensi $127 \times 12,7 \times 3 \mathrm{~mm}$. untuk uji Tarik dimensi yang dibentuk 60x15x5 mm. Cetakan dibungkus dengan alumunium foil untuk menghindari reaksi kimia yang mungkin terjadi antara PVC dengan komposit polyurethane sementara spesimen untuk pengujian densitas didapat dari potongan uji bending dan uji tarik dengan dimensi spesimen $1 \times 1 \times 1 \mathrm{~cm}$. Nilai fraksi massa tersebut berdasarkan pada percobaan karena diatas nilai tersebut serat tidak bisa diaduk 
dalam larutan polyurethane dikarenakan massa jenis serat fiberglass $2.54 \mathrm{gr} / \mathrm{cm}^{3}$

\section{Pengujian kuat lentur}

Kekuatan lentur digunakan untuk menunjukkan kekakuan dari suatu material ketika dibengkokkan. Pengujian kelenturan dilakukan dengan metode three point bend, dimana spesimen diletakkan pada kedua tumpuan dan dilakukan pembebanan di tengah spesimen. Mesin yang digunakan adalah mesin uji bending milik Unair Surabaya. Prosedur pengujian menurut standar ASTM D790. Dimensi spesimen yang diuji sesuai standar tersebut ialah sebesar 127x12.7x3 mm.

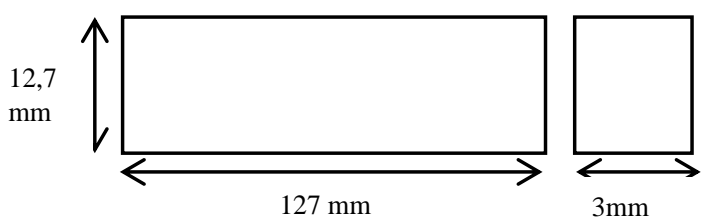

Gambar 1. Dimensi spesimen uji bending

Kekuatan lentur suatu material dapat dihitung dengan persamaan berikut:

$\sigma_{f}=\frac{3 P L}{2 b d^{2}}$

Keterangan :

$\sigma_{f}=$ kekuatan lentur $\left(\mathrm{Kg} / \mathrm{cm}^{2}\right)$

$L=$ Support span $(\mathrm{cm})$

$P=$ Beban patah $(\mathrm{Kg})$

$b=$ lebar spesimen $(\mathrm{cm})$

$d=$ tebal spesimen $(\mathrm{cm})$

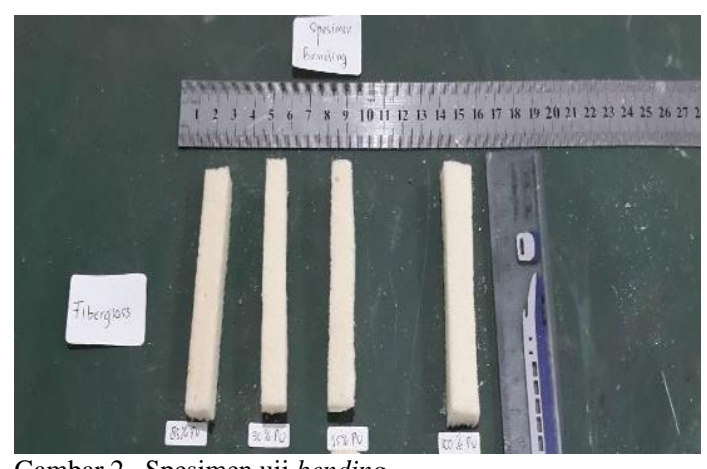

Gambar 2. Spesimen uji bending

\section{Pengujian Tarik}

Pengujian tarik dilakukan untuk mengetahui kekuatan tarik suatu material serta modulus elastisitasnya. Mesin yang digunakan adalah mesin uji bending milik Unair Surabaya. Prosedur pengujian menurut standar ASTM D-3039 00. Dimensi spesimen yang diuji sesuai standar tersebut ialah sebesar 60x15x5 mm.
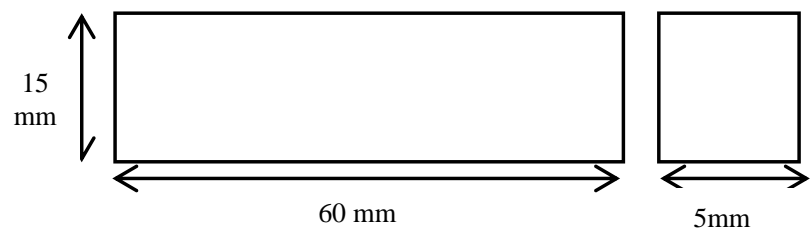

Gambar 3. Dimensi spesimen uji Tarik

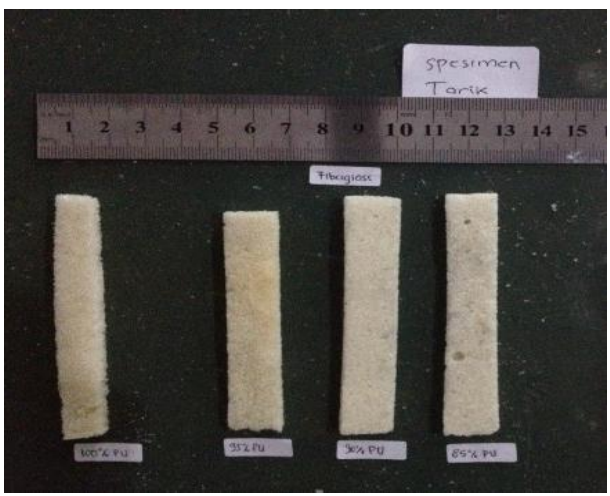

Gambar 4. Spesimen uji tarik

\section{E. Pengujian Densitas}

Uji densitas menggunakan ASTM C271-99. Pengujian dilakukan dengan perhitungan massa dan volume dari masingmasing spesimen komposit.

\section{HASIL DAN PEMBAHASAN}

\section{A. Uji Bending}

Uji bending komposit serat dilakukan di laboratorium farmasi Univeritas Airlangga Surabaya. Dari pengujian kekuatan lentur yang telah dilakukan, diperoleh hasil data sebagai berikut :

Tabel 1.

Hasil Pengujian kekuatan lentur PU murni (70PPI:30PPG) komposit PU- serat gelas\%

\begin{tabular}{ccccc}
\hline \hline & PU murni & \multicolumn{3}{c}{ Komposit PU } \\
& (70PPG:30PPI) & \multicolumn{2}{c}{ (70PPI:30PPG)-FG\% } \\
\hline $\begin{array}{c}\text { Fraksi massa (\%) } \\
\text { Kekuatan Lentur } \\
\text { (Mpa) }\end{array}$ & 55.88 & 5 & 10 & 15 \\
\hline \hline
\end{tabular}

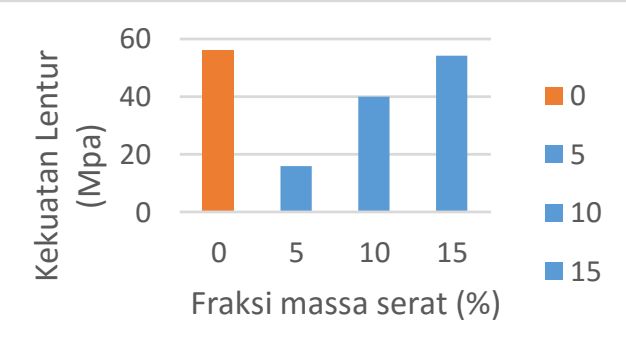

- PU murni (70PPI:30P $P G)$

Komposit PU (70PPI:30P PG)-FG\%

Gambar 5. Hasil uji bending

Berdasarkan Tabel 1 dan Gambar 5 menunjukkan hasil uji bending PU murni, komposit serat gelas dengan perbandingan penyusun polyurethane 70PPI:30PPG. Diketahui bahwa nilai kekuatan lentur polyurethane murni tanpa serat sebesar 55.88 MPa. Ketika ditambahkan serat gelas sebesar 5\% kekuatan lentur menurun menjadi 15.96 MPa. Pada fraksi serat gelas $10 \%$ kekuatan lentur naik yaitu sebesar 39.91 MPa dan terus naik sebesar 54.28 MPa ketika fraksi massa serat sebesar $15 \%$. Namun ketika ditambahkan serat kekuatan lentur terus naik dari fraksi massa serat gelas 5\%, 10\%, dan $15 \%$. Hal ini membuktikan bahwa jika semakin banyak serat gelas ditambahkan ke PU maka kekuatan lenturnya akan menyaingi kekuatan lentur PU murni. 
Hal tersebut disebabkan karena memang pada dasarnya kekuatan mekanik pada serat gelas tinggi jika dibandingkan dengan serat natural bambu. khusus pada komposit PU-serat bambu, penambahan serat ini akan mengakibatkan penurunan nilai kekuatan dan sifat mekanik dari material komposit [6]. Sifat mekanik disini adalah bending (kelenturan) dan uji tarik. Dikarenakan pada proses alkalisasi bertujuan untuk meningkatkan ikatan interface pada komposit tetapi hal ini membuat serat menjadi sangat rapuh karena lignin yang di dalam serat dihilangkan lewat proses tersebut. Tetapi pada penambahan fraksi serat selanjutnya nilai kekuatan bending akan ikut meningkat.

Kurangnya serat yang ditambahkan akan menurunkan kemampuan komposit untuk menahan beban yang diberikan [5], sehingga dapat dilihat dalam bentuk patahannya setelah dilakukan pengujian terlihat lebih getas dikarenakan kurangnya serat yang ditambahkan. Berdasarkan gambar 4.6 diatas dapat disimpulkan bahwa semakin banyak penambahan serat ke dalam komposit maka akan semakin meningkatkan nilai kekuatan lentur terhadap beban yang diterima oleh material komposit.

\section{B. Uji Tarik}

Cetakan untuk uji tarik dibuat menggunakan seng yang dibentuk dengan dimensi $60 \times 15 \times 5 \mathrm{~mm}$ sesuai dengan ASTM D-3039 00. Yang mana dibuat dengan metode blending. Dari pengujian kekuatan tarik yang telah dilakukan, diperoleh hasil data sebagai berikut:

Tabel 2.

Hasil Pengujian kekuatan tarik PU murni (70PPI:30PPG), dan komposit PU-Serat gelas

\begin{tabular}{ccccc}
\multicolumn{4}{c}{ PU-Serat gelas } \\
\hline & PU murni & \multicolumn{3}{c}{ Komposit PU } \\
(70PPG:30PPI) & \multicolumn{2}{c}{ (70PPI:30PPG)-FG\% } \\
\hline $\begin{array}{c}\text { Fraksi massa (\%) } \\
\begin{array}{c}\text { Kekuatan Tarik } \\
\left(\mathrm{N} / \mathrm{cm}^{2}\right)\end{array}\end{array}$ & - & 5 & 10 & 15 \\
\hline \hline
\end{tabular}

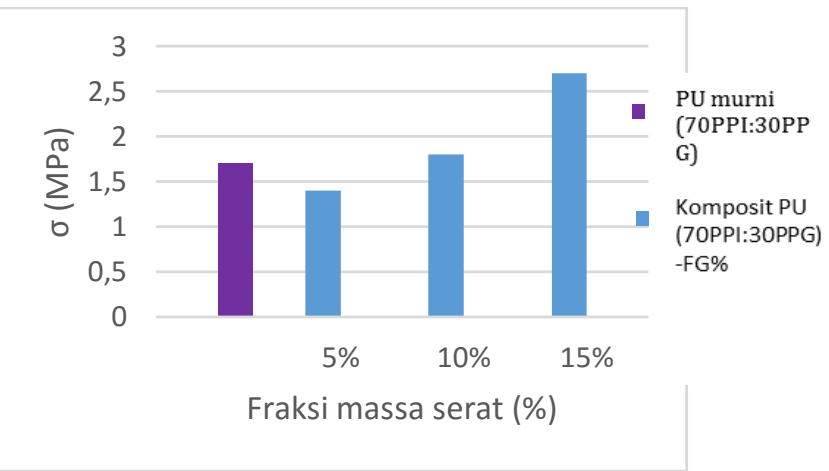

Gambar 6. Hasil uji Tarik

Dari Tabel 2 dan Gambar 6 diatas dapat diketahui bahwa pada komposit PU-serat gelas dengan fraksi massa $15 \%$ serat gelas mempunyai nilai kekuatan tarik tertinggi sebesar 2.7 MPa. Sedangkan pada spesimen $100 \%$ PU mempunyai nilai kekuatan tarik sebesar 1.7 MPa.

Berdasarkan hasil pengujian, nilai kekuatan tarik terendah ada pada spesimen komposit PU-serat gelas 5\% sebesar 1.4 $\mathrm{MPa}$. Dari hasil pengujian tarik didapatkan hasil bahwa PU murni mempunyai nilai kekuatan tarik hampir sama dengan yang komposit PU-serat gelas 10\% sebesar 1.8 MPa. Namun dengan penambahan serat gelas kekuatan tarik bisa lebih tinggi.

Sama halnya dengan spesimen uji kelenturan hal yang menyebabkan spesimen komposit PU-serat gelas lebih tinggi adalah karena memang pada dasarnya kekuatan mekanik pada serat gelas lebih tinggi dibandingkan serat bambu. namun pada dasarnya kekuatan serat bambu hamper menyamai kekuatan serat gelas, tetapi seiring bertambah banyaknya fraksi massa serat maka akan menambah kekuatan tarik dari material komposit tersebut [5] [6].

\section{Uji Densitas}

Pengujian densitas dilakukan dengan cara menghitung massa dan volume dari masing-masing spesimen untuk diketahui massa jenisnya.

Pada hasil pengukuran komposisi penyusun polyurethane 70:30 murni didapat densitas sebesar $0.115 \mathrm{~g} / \mathrm{cm}^{3}$. Sementara pada komposisi komposit PU-Serat gelas diketahui bahwa pada fraksi massa $5 \%$ didapat densitas sebesar $0.083 \mathrm{~g} / \mathrm{cm}^{3}$, kemudian pada fraksi massa $10 \%$ densitas meningkat menjadi $0.11 \mathrm{~g} / \mathrm{cm}^{3}$ dan pada $15 \%$ meningkat menjadi $0.128 \mathrm{~g} / \mathrm{cm}^{3}$.

Sedangkan pada hasil pengujian komposisi penyusun polyurethane 70:30 murni didapat densitas sebesar $0.11 \mathrm{~g} / \mathrm{cm} 3$. Sementara pada komposisi komposit PU-Serat gelas diketahui bahwa pada fraksi massa 5\% didapat densitas sebesar 0.05 $\mathrm{g} / \mathrm{cm}^{3}$, kemudian pada fraksi massa $10 \%$ densitas meningkat menjadi $0.09 \mathrm{~g} / \mathrm{cm}^{3}$ dan pada $15 \%$ meningkat menjadi 0.10 $\mathrm{g} / \mathrm{cm}^{3}$. Setiap penambahan serat akan menaikkan densitas. Densitas juga dipengaruhi oleh fraksi massa perbandingan PU A dan PU B. semakin besar fraksi massa PU A maka semakin besar nilai densitasnya.

Tabel 3.

Perbandingan densitas PU murni (70PPI:30PPG), komposit PU-serat gelas dengan Pengukuran

\begin{tabular}{ccccc}
\hline & PU murni & \multicolumn{3}{c}{ Komposit PU (70PPI:30PPG)- } \\
& (70PPG:30PPI) & \multicolumn{3}{c}{ FG\% } \\
\hline $\begin{array}{c}\text { Fraksi massa } \\
(\%)\end{array}$ & - & 5 & 10 & 15 \\
Densitas & & $0.083 \pm$ & $0.11 \pm 0.00$ & $0.128 \pm 0.0$ \\
$\left(\mathrm{~g} / \mathrm{cm}^{3}\right)$ & $0.115 \pm 0.0009$ & 0.0039 & 41 & 078 \\
\hline \hline
\end{tabular}

Tabel 4.

Perbandingan densitas PU murni (70PPI:30PPG), komposit PU-serat gelas dengan Pengujian

\begin{tabular}{ccccc}
\hline \hline & PU murni & \multicolumn{2}{c}{ Komposit PU (70PPI:30PPG)-FG\% } \\
\hline (70PPG:30PPI)
\end{tabular}




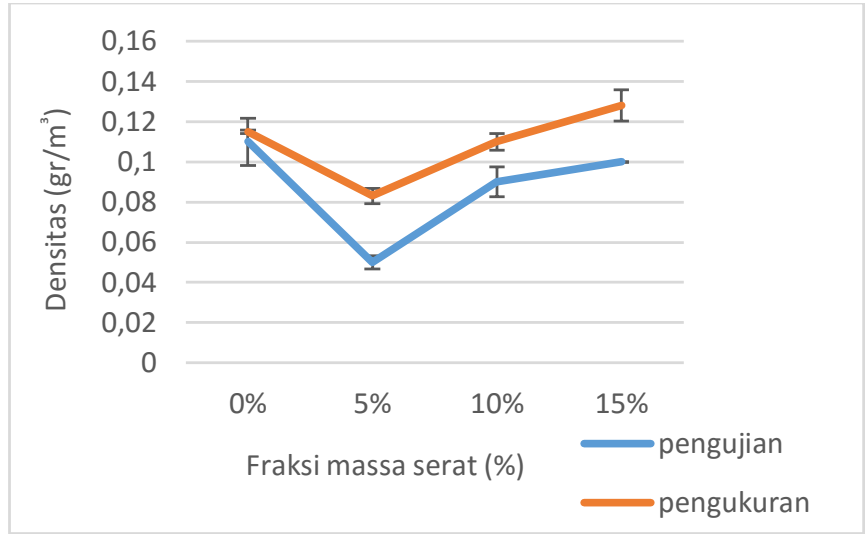

Gambar 7. Hasil Uji Densitas

Pada hasil pengukuran dan pengujian ternyata didapatkan perbedaan hasil densitas antara keduanya, namun trennya tetap sama. Dan dari Gambar 4.8 dapat diartikan bahwa semakin banyak penambahan serat maka akan semakin meningkatkan massa jenis atau densitasnya. Terbukti dengan bertambah nya fraksi massa serat maka nilai densitas akan terus meningkat dibuktikan dengan tabel 4.8

Tetapi bila dibandingkan dengan teori nilai densitasnya turun, dikarenakan gelembung atau foam dari spesimen polyurethane serat gelas lebih banyak dibanding PU. Jumlah void yang banyak akan mengakibatkan jumlah gas dalam void akan bertambah [7]. Gas ini mempunyai kekuatan mekanik yang dapat menurunkan sifat mekanik dari foam atau void tersebut. Berarti akan mengakibatkan turunnya densitas pula. Hal ini dibuktikan dengan nilai densitas eksperimen yang lebih kecil daripada teori. Karena pada saat eksperimen, polyurethane mengembang dengan volume tertentu dan semakin mengembang akan semakin banyak void dan gas.

\section{UCAPAN TERIMAKASIH}

Penulis berterimakasih banyak kepada Program Riset Unggulan Jurusan tahun 2016 yang didanai oleh Jurusan Teknik Material dan Metalurgi FTI-ITS.

\section{DAFTAR PUSTAKA}

[1] M.M Schwartz., 1984 “Composite Materials Handbook”, McGraw-Hill Inc, New York.

[2] H. Nurdin. Zona Teknik ISSN 1978-1741, Pengaruh Penggunaan Jenis Serat Pada Komposit Polimer Terhadap Kekuatan Tarik. Volume 3 No.2: 143-150

[3] M. Farid, T. Heryanto. 2013. Correlation of Normal Incidence Sound Absorption Coefficient (NAC) and Random incidence Sound Absorption Coeffiecient (RAC) of Polyester/Ramie Fibre Composite Materials. Advanced Material Research. Vol. 789, pp.269-273

[4] M. Farid, H. Ardhyananta, V.M.Pratiwi, S.P Wulandari. 2015. Correlation between Frequency and Sound Absorption Coeffiecient of Polymer Reinforced Natural Fibre. Advanced Materials Research, Vol. 1112, pp. 329-332.

[5] Gayatri. 2014. Processing and Characterization of Pultruded Polyurethane Composites. Huntsman International LLC. MichiganUSA.

[6] M. Rahman, M. et al. 2005. Design and Construction of Muffler for Engine Exhaust Noise Reduction. Proceedings of the International Conference on Mechanical Engineering

[7] K. Sivertsen. 2007. "Polymers Foams". 3.063 polymer physics. 